\title{
Dyke-Davidoff-Masson syndrome: a combination of clinical and radiological signs not to be missed
}

Síndrome de Dyke-Davidoff-Masson: uma combinação de sinais clínicos e radiológicos para não serem esquecidos

Wladimir Bocca Vieira de Rezende Pinto, Paulo Victor Sgobbi de Souza, José Luiz Pedroso, Orlando Graziani Povoas Barsottini

A 21-year-old man presented with complex partial status epilepticus. His past medical history was marked by epilepsy and his examination disclosed atrophy of the right limbs and hemiparesis in the same side of the body. A brain CT scan showed atrophy of the entire left hemisphere, with prominent sulci, enlargement of the lateral ventricle and overdevelopment of the frontal sinuses on the left side (see figure).
Dyke-Davidoff-Masson syndrome is an uncommon congenital or childhood-onset acquired neurologic syndrome, presenting mainly with complete hemiparesis, recurrent seizures and non-progressive chronic encephalopathy ${ }^{1,2}$. Neuroimaging features are characterized by unilateral cerebral atrophy with ipsilateral hypertrophy of paranasal sinuses ${ }^{2}$.
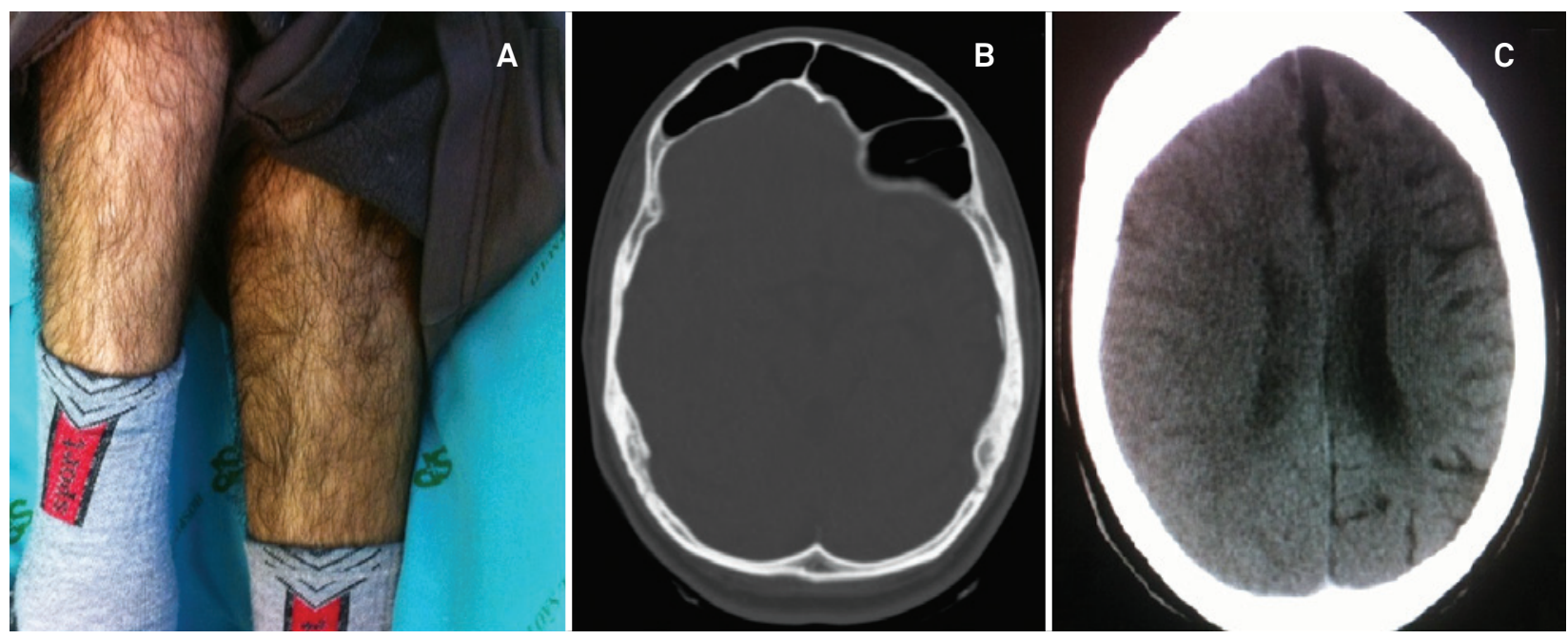

Figure. (A) examination discloses marked right-side atrophy, compared with left side; (B, C) brain computerized tomography shows atrophy of the entire left cerebral hemisphere. Note the prominent sulci, enlargement of the lateral ventricle and overdevelopment of the frontal sinuses on the left side.

\section{References}

1. Dyke CG, Davidoff LM, Masson CB. Cerebral hemiatrophy with homolateral hypertrophy of the skull and sinuses. Surg Gynecol Obstet 1933;57:588-600.
Chand G, Goel R, Kapur R. Dyke-Davidoff-Masson syndrome. Arch Neurol 2010;67:1026.

Department of Neurology, Division of General Neurology, Universidade Federal de São Paulo, São Paulo SP, Brazil.

Correspondence: Dr. José Luiz Pedroso; Rua Botucatu 740;04023-900 São Paulo SP - Brasil; E-mail: jlpedroso.neuro@gmail.com

Conflict of interest: There is no conflict of interest to declare.

Received 27 May 2013; Received in final form 26 June 2013; Accepted 03 July 2013. 